\title{
EMBOLIA GASOSA EM NEUROCIRURGIA
}

\author{
Pedro Garcia Lopes * \\ JuVEnal DE Souza Rogério * \\ OsWaldo Ricciardi-Cruz **
}

A embolia gasosa por via venosa é uma complicação das intervenções neurocirúrgicas realizadas com o paciente em posição sentada. Michenfelder e col. ${ }^{9}$, em 1.114 intervenções feitas nesta posição, sendo 418 craniectomias occipitais, observaram embolias em 11 dêstes últimos casos. Altenburg (cit. por Michenfelder e col. ${ }^{10}$ ) em 635 intervenções assinalou embolia em $3,8 \%$ dos casos. Em revisão da literatura, Tisovec e Hamilton ${ }^{12}$ encontraram incidências que variavam de 2,6 a $15 \%$. A mortalidade nos casos de embolia é grande; Ericson e col. ${ }^{2}$ verificaram que nos casos relatados na literatura, a mortalidade foi de $73 \%$.

Na Clínica Neurológica da Faculdade de Medicina da Universidade de São Paulo, dentre 394 intervenções neurocirúrgicas feitas com os pacientes em posição sentada, ocorreu embolia gasosa determinando êxito letal em três casos. A freqüência e a gravidade dessa complicação, que deve ser considerada em virtude da crescente utilização da posição sentada nas intervenções neurocirúrgicas, motivam a apresentação dêste trabalho.

\section{O B S E R V A C O E S}

Caso 1 - Z.J.C., sexo masculino, branco, com 38 anos de idade (Registro H.C. 909.163), internado com o diagnóstico de processo expansivo no ângulo ponto-cerebelar esquerdo. Exames de rotina confirmaram a presença da neoplasia.

Intervenção cirürgica - Anestesia geral com nesdonal (2,5\%), inoval e protóxido de azôto $(66 \%)$, entubação endotraqueal e contrôle do rítmo cardiaco com estetocópio pré-cordial. Paciente colocado em posição sentada e incisados os planos superficiais. Craniectomia occipital, utilizando-se cêra de osso, irrigação continua com sôro fiśológico e rigorosa hemostasia. Alguns minutos após o inicio da craniectomia ocorreram alterações circulatórias e parada cardíaca sem que, prèviamente, a ausculta indicasse qualquer alteração do rítmo cardiaco; imediatamente, o paciente foi colocado em decúbito dorsal, sendo feita massagem cardiaca externa sem resultado. A necrópsia mostrou colapso pulmonar parcial e enfizema pulmonar, além de um neurinoma do nervo acústico esquerdo.

Caso 2 - G.C.O., sexo masculino, branco, com 30 anos de idade (Registro H.C. 911.646), admitido com o díagnóstico de malformação occipito-cervical.

Intervenção cirúrgica - Anestesia geral com nesdonal (2,5\%), inoval e protóxido de azôto $(66 \%)$, entubação endotraqueal e contrôle do rítmo cardíaco com estetoscópio pré-cordial. Paciente colocado em posição sentada e incisão dos planos

Clínica Neurológica, Departamento de Neuro-Psiquiatria, Faculdade de Medicina da Universidade de São Paulo. * Médico estagiário; ** Docente. 
superficiais. Craniectomia occipital, usando-se cêra de osso, sôro fisiológico e rigorosa hemostasia. Pouso tempo depois de iniciada a craniectomia, foi ouvido, por meio do estetoscópio pré-cordial, um ruido forte e, imediatamente após, ocorreu queda da pressāo arterial e aceleração do pulso, seguido de parada cardiaca. Colocado o paciente em decúbito dorsal, foi feita massagem cardiaca externa e, logo depois, toracotomia para massagem cardiaca a céu aberto, tudo sem resultado. A necrópsia demonstrou invaginação basilar, nada sendo encontrado de anormal no coração e nos pulmões.

Caso 3 - J.A.C., sexo masculino, branco, com 5 anos de idade (Registro H.C. 920.940), internado com diagnóstico de processo expansivo no verme cerebelar. Exames de rotina confirmaram o diagnóstico.

Intervenção cirúrgica - Anestesia geral com nesdonal (2,5\%), inoval e protóxido de azôto $(66 \%)$, entubação endotraqueal e contrôle do rítmo cardiaco com estetoscópio pré-cordial. Paciente colocado em posição sentada e incisados os planos superficiais. Graniectomia occipital, fazendo-se uso de cêra de osso, sôro fis ológico e rigorosa hemostasia. Durante a craniectomia, ocorreu alteração da pressão arterial seguida de parada cardiaca, que não regrediu com o decúbito dorsal e massagem cardiaca externa. Um exame radiológico do tórax feito após o óbito mostrou haver grande quantidade de ar ao nível das áreas cardíacas. A necrópsia mostrou a presença de um meduloblastoma no verme cerebelar, nada sendo encontrado de anormal no coração e nos pulmões.

\section{COMENTARIOS}

A posição sentada determina, nos vasos cranianos de pacientes submetidos à intervenções neurocirúrgicas, uma pressão subatmosférica; visto que os vasos da diploe não se colabam, há entrada de ar que vai localizar-se no coração direito. Várias eram as hipóteses sôbre o mecanismo que provocava os sinais e sintomas da embolia gasosa. Bierhans e Hintze (cit. por Emeri ${ }^{1}$ ), mediante trabalho experimental com cães, concluiram que o mecanismo responsável é a obstrução mecânica, excluindo a ação reflexa, visto que os distúrbios não são afastados pela vagotomia bilateral ou pela atropinização do animal.

Não existem meios seguros para prevenir êste tipo de embolia, mas algumas medidas podem ser tomadas para diminuir as possibilidades de ocorrência desta complicação. Diversos autores $5,8,9,11,12$ consideram úteis para a prevenção da embolia, os seguintes cuidados; utilizar respiração controlada com pressão positiva durante a anestesia; evitar o uso de protóxido de azôto na anestesia ou, então, usá-lo em baixa concentração (menos de 50\%), devendo sua administração ser interrompida no início da craniectomia pois Munson e Merrick ${ }^{11}$, em trabalho experimental, demonstraram que quando é usado êste anestésico, a quantidade de ar necessária para provocar a morte é menor; aumentar a pressão venosa alguns minutos antes da craniectomia (circuito fechado de anestesia, ventilação com pressão positiva intermitente, meias elásticas, macacões pressurizados); usar durante a craniectomia, cêra de osso e sôro fisiológico.

Quando ocorre a embolia, é importante o diagnóstico precoce. De responsabilidade única e exclusiva do anestesista, êste diagnóstico baseia-se nos primeiros sinais de embolia: alteração da ausculta cardiaca, aparecendo um som forte e rude ("mill-whell"); alterações hemodinâmicas (aumento da pressão venosa e queda da arterial); modificações nas concentraçōes dos 
gases no sangue arterial e no bióxido de carbono e nitrogênio espirados. $O$ "mill-whell", embora seja o sinal mais característico da embolia, não é o mais freqüente e só se produz quando é grande a quantidade de ar. Maroon e col. ${ }^{6}$, realizando experiências em cães, necessitaram injetar, ràpidamente, 30 a $40 \mathrm{ml}$ de ar na veia para obterem o "mill-whell", coincidindo êstes dados com os de Shivpuri (cit. por Maroon e col. ${ }^{6}$ ). Michenfelder e col. ${ }^{9}$, em 11 casos de embolia, constataram a presença de "mill-whell" em apenas três. Nos casos relatados nêste trabalho, sòmente um apresentou o "mill-whell".

Algumas proviđências podem ser tomadas visando a facilitar o diagnóstico da embolia gasosa: estetoscópio esofágico, cateterização do átrio direito para contrôle da pressão venosa, eletrocardiograma durante o ato cirúrgico e dosagem dos gases inspirados e espirados $9,10,12$. Ültimamente, está sendo usado um monitor cardiaco ultrasônico que registra alterações do murmúrio cardíaco com quantidade mínima de ar ${ }^{6,7}$.

O tratamento da embolia visa impedir a entrada de ar no sistema venoso (tamponamento dos vasos da diploe; aumento da pressão venosa) e esvaziamento das câmaras cardiacas, sendo recomendadas: a aspiração do ar através do cateter intra-cardíaco; a manobra de Durant que consiste em colocar o paciente em decúbito lateral esquerdo e com a cabeça em nivel inferior; a interrupção no uso do protóxido de azôto, substituindo-o por oxigênio a $100 \%$ com pressão positiva; o uso de vasopressores com ação inotrópica positiva; a massagem cardiaca externa. A aspiração direta do coração e a massagem cardíaca a céu aberto não dão resultado, devido ao tempo necessário para ser feita a toracotomia. Michenfelder e col. ${ }^{9}$ não assinalaram caso algum de óbito dentre os 11 que apresentaram embolia, utilizando principalmente a aspiração do ar por cateter intra-cardíaco. Ericson e col. ${ }^{2}$, em 7 casos, recuperaram 5 pacientes com massagem cardíaca externa e manobra de Durant. Nossos casos foram todos fatais, apesar de usarmos a manobra postural e massagem cardíaca externa e, em um dêles (caso 2), massagem cardíaca direta mediante toracotomia.

Analisando todos os dados relatados, verifica-se a grande importância da cateterização do coração, seja para diagnóstico precoce, seja para o tratamento. Por outro lado, a utilização do monitor cardíaco ultrasônico pode ser de grande valia no diagnóstico precoce da embolia gasosa.

\section{RESU MO}

São relatados três casos em que ocorreram embolias gasosas e êxito letal em pacientes submetidos à intervenções neurocirúrgicas em posição sentada. As medidas preventivas e os métodos de diagnóstico e tratamento são comentados.

\section{S U M M A R Y}

Air embolism in neurosurgery: report of three fatal cases

Three fatal cases of air embolism in which the patients were operated in the sitting position are reported. Preventive care, methods for diagnostical purposes and tretment resources are discussed. 
R E F E R E N I A S

1. EMERY, E. R. J. - Air embolism: a report of two cases, one treated sucessfully. Anaesthesia $17: 455,1962$

2. ERICSON, J. A.; GOTTLIEH, J. D. \& SWETT, R. B. - Closed chest massage in the treatment of venous air. New Eng. J. Med. 270:1353, 1964.

3. HAMBY, W. B. \& TERRY, R. N. - Air embolism in operations done in the sitting position. A report of five fatal cases and one of rescue by a simple manoeuvre. Surgery 31:212, 1952.

4. HEWER, A. J. H. \& LOGUE, V. - Methods of increasing the safety of neuroanesthesia in the sitting position. Anaesthesia 17:476, 1962 .

5. HUNTER, A. R. - Air embolism in the sitting position. Anaesthesia 17:467, 1962.

6. MAROON, J. G.; GOODMAN, J. M.; HORNER, T. G. \& CAMPBELL, R. L. Detection of minute venous air emboli with ultrasound. Surgery Gynec. Obstet. $127: 1236,1968$.

7. MAROON, J. G.; EDMONDS-SEAL, J. \& CAMPBELL, R. L. - An ultrasonic method for detecting air embolism. J. Neurosurg. 31:196, 1969.

8. MARX, G. F.; STEEN, S. N.; FOSTER, E. S.; JADWAT, C. M. \& KEPES, E. R. Air embolism during neurosurgery. N.Y.St.J.Med. 68:2801, 1968.

9. MICHENFELDER, J. D.; TERRY Jr., H. R.; DAW, E. F. \& MILLER, R. H. Air embolism during neurosurgery: a new method of treatment. Anesth. Analg. 45:390, 1966 .

10. MICHENFELDER, J. D.; GROVERT, G. A. \& REHDER, K. - Neuroanesthesia. Anesthesiol. 30:65, 1969.

11. MUNSON, E. S. \& MERRICK, H. C. - Effect of nitrous oxide on venous air embolism. Anesthesiol. 27:783, 1966

12. TISOVEC, L. \& HAMILTON, W. K - New considerations in air embolism during operation. J. Am. med. Ass. 201:376, 1967.

Clinica Neurológica - Faculdade de Medicina, Universidade de São Paulo Caixa Postal $\$ 461$ - São Paulo, SP — Brasil. 